Research note

\title{
Comparison of gene expression under in vitro and ex vitro conditions during rooting of grape cuttings through mRNA differential display
}

\author{
Pious Thomas ${ }^{1, *} \&$ John W. Schiefelbein ${ }^{2}$ \\ ${ }^{1}$ Division of Biotechnology, Indian Institute of Horticultural Research, Hessarghatta Lake, Bangalore \\ 560 089, India; ${ }^{2}$ Department of Molecular, Cellular and Developmental Biology, University of Michigan, Ann \\ Arbor, MI 48109, USA (*requests for offprints; Fax: +91-80-28466291; E-mails: pioust@iihr.res.in; \\ pioust@vsnl.com)
}

Received 3 February 2004; accepted in revised form 6 April 2004

Key words: adventitious rooting, gene expression, in vitro, mRNA differential display, stem cutting, Vitis vinifera

\begin{abstract}
An mRNA differential display (DD) analysis during rooting in grape cuttings was carried out to determine whether gene expression patterns differed under in vitro and ex vitro conditions. The four tissue samples for differential display and subsequent Northern hybridization analyses included control stem tissue from in vitro and ex vitro sources, microcuttings planted in MS based in vitro rooting medium and softwood cuttings planted in ex vitro soil medium, both collected $48 \mathrm{~h}$ after planting. DD autoradiographs showed gross similarity in banding pattern between in vitro and ex vitro stem tissue, whether constitutive or induced. Northern blot analysis of a few bands that appeared to be differentials did not indicate them as true positives. The results suggested that gene expression pattern during physiological processes such as rooting may be identical under in vitro and ex vitro conditions.
\end{abstract}

Abbreviations: DD RT-PCR - differential display reverse transcriptase polymerase chain reaction; MS medium - Murashige and Skoog (1962) medium; IAA - indole 3 acetic acid

In vitro propagation differs from the ex vitro in a number of aspects such as the planting medium and nutrient supply, duration and concentration of growth regulator treatment, type and age of tissue, special environment on account of a contained vessel and heterotrophy or mixotrophy in contrast to autotrophy ex vitro. Plant growth is governed by the expression of numerous genes which are turned on or off under specific developmental stages or in response to external stimuli. To our knowledge, no efforts have been made to assess whether gene expression profiles are identical or different under in vitro and ex vitro environments. This question when put informally before divergent group of plant biologists, the opinion was found to be divided.

Adventitious root formation constitutes an appropriate basic plant process to study gene expression profiles under in vitro and ex vitro conditions, and the availability of well characterized propagation protocol using softwood leafy cuttings in vitro (Thomas, 1998) and in vivo (Thomas and Schiefelbein, 2004) which are amenable to nucleic acid extraction makes grapevine an ideal system for such studies. Leafy grape microcuttings cultured in vitro or softwood cuttings planted in vivo showed signs of root formation (e.g. basal swelling) within two days after planting 
and this period appeared to correspond to early rooting inductive phase (Thomas, 1998; Thomas and Schiefelbein, 2004). mRNA differential display studies using RNA isolated from stem tissue of leafy cuttings $48 \mathrm{~h}$ post-planting and control shoots has helped in demonstrating differential gene expression during early rooting period (Thomas and Schiefelbein, 2002a), isolation and characterization of some genes involved in rooting viz. $V v A D F$ (Thomas and Schiefelbein, 2002b), VvPRP1 and VvPRP2 (Thomas et al., 2003) and demonstration of their expression in various organs of soil-grown plants.

Differential display Reverse transcriptase Polymerase chain reaction (DD RT-PCR) technique (Liang and Pardee, 1992) is a very powerful tool for studying gene expression at any given time in two or more samples and this method still commands popularity in diverse biological systems over all other competitive gene discovery technologies (Liang, 2002). In this study, we have used differential display technology to assess whether the gene expression pattern is identical or different under in vitro and ex vitro conditions using grape softwood cuttings in the rooting phase.

The studies were carried out using grape (Vitis vinifera L.) cv. Arka Neelamani. The in vitro stocks were grown on MS (Murashige and Skoog, 1962) medium containing $3 \%$ sucrose and $1.0 \mu \mathrm{M}$ indole 3 acetic acid (IAA) at $26 \pm 2{ }^{\circ} \mathrm{C}$ under 16-h photoperiod $\left(40-50 \mu \mathrm{mol} \mathrm{m}^{-2} \mathrm{~s}^{-1}\right)$ provided by cool - white fluorescent tubes, with subculturing at 1-3 month interval as described previously (Thomas, 1998). Single node microcuttings measuring about $1-1.5 \mathrm{~cm}$ with lamina at the apical end were prepared from stock cultures at 1.52 months after culturing.

The ex vitro stocks were comprised of 2 month old in vivo established, tissue culture derived plants and the shoots further propagated using singlenode cuttings (Thomas and Schiefelbein, 2004). These plants were raised under similar conditions as in vitro plants but for a slightly higher light intensity $\left(60-80 \mu \mathrm{mol} \mathrm{m}^{-2} \mathrm{~s}^{-1}\right)$ and planting in Sunshine Mix $1^{\circledR}$ (Sungrow Horticulture, Washington DC, USA $)$ in mini pots $(8 \times 8 \times 7.5 \mathrm{~cm})$. Single node softwood cuttings with lamina at top end were prepared from these stocks and the lower half of all the cuttings were dipped for $15 \mathrm{~min}$ in $100 \mu \mathrm{M}$ IAA prepared in half strength MS medium $(\mathrm{pH}$ 6.0) before planting. The pots were ar- ranged in plastic trays and covered with transparent domes to avoid desiccation.

RNA was extracted from the stem tissue excluding the leaf part as described by Thomas and Schiefelbein (2002a). The four sources of RNA for differential display were (control 1) stem tissue from the in vitro grown stock, (control 2) ex vitro grown stock, (3) microcuttings grown for 48 -h in the in vitro medium as described above and (4) softwood cuttings $48 \mathrm{~h}$ post-planting in the Sunshine Mix $1^{\circledR}$ medium in vivo.

DD RT-PCR (Liang and Pardee, 1992) was performed as per Reuber and Ausubel (1995) using the RNAImage ${ }^{\mathrm{TM}}$ kitl (GenHunter Corporation, Nashville, TN) following kit instructions. There were 24 PCR combinations per RNA sample resulting from three anchored primers viz., $\mathrm{H}-\mathrm{T}_{11} \mathrm{~A}, \mathrm{H}-\mathrm{T}_{11} \mathrm{G}$ and $\mathrm{H}-\mathrm{T}_{11} \mathrm{C}$ (designated as $\mathrm{A}, \mathrm{G}$ and $\mathrm{C}$ respectively) and eight arbitrary primers (AP 1-8) as per the kit. PCR products from the four RNA sources were run side by side and the differentially expressed bands were detected after subjecting the gels to autoradiography. The autoradiographs were observed for the bands that were specific to in vitro or ex vitro tissue alone, either constitutive or induced. Six primer combinations (AxAP4; AxAP6, AxAP8, GxAP2, CxAP5 and CxAP7), which showed some differential bands, were run a second time to confirm the observations.

The cDNA bands of interest were isolated by aligning the autoradiograph to the gel as per kit instructions and was further PCR amplified in a $40 \mu \mathrm{l}$ reaction using the same set of anchored and arbitrary primers that generated the original band. The reamplified DNA bands were gel-purified using the QIAquick kit (Qiagen) and were used in probe preparation for Northern hybridization analysis.

RNA from the four treatment sources was used in Northern hybridization analysis. RNA ( 8 or $10 \mu \mathrm{g})$ was electrophoresed in denaturing $(2.2 \mathrm{M}$ formaldehyde) agarose gels (1\%), transferred onto GeneScreen (NEN Research Products) membranes using 10× SSC as per manufacturers instructions and four such membranes were prepared. Probes were prepared using Random Priming kit (Roche Molecular Biochemicals) and $\alpha-{ }^{32} \mathrm{P}-\mathrm{dATP}$. Partial cDNA clones of two genes that are differentially expressed during rooting and are fairly well characterized viz., $V v A D F$ (Thomas 
and Schiefelbein, 2002b) and VvPRPI (Thomas et al., 2003) were used as the positive controls. Pre-hybridization, hybridization and washing were performed as described earlier (Thomas and Schiefelbein, 2002b).

Examination of DD autoradiographs indicated a number of differentials that were induced both in vitro and ex vitro cuttings during rooting inductive phase but the gene expression profile under the two conditions, whether constitutive or induced, was largely similar (Figure 1). Scoring revealed that over $99 \%$ of the bands were identical between the two situations. Four bands that appeared to be specific to in vitro tissue (designated as $\left.\mathrm{I}_{1-4}\right)$ and four bands specific to ex vitro $\left(\mathrm{E}_{1-4}\right)$ were short-listed for detailed studies (Figure 1; Table 1). Northern hybridization analysis using the four putative in vitro specific cDNA probes showed similar positive signal from all the four test RNA samples for $I_{1}, I_{2}$ and $I_{4}$ while no signal was detected for $\mathrm{I}_{3}$ (figures not presented). Northern blot using four putative ex vitro tissue specific cDNA bands showed a positive signal for $\mathrm{E}_{2-4}$ probes while no signal was observed for $\mathrm{E}_{1}$. The control cDNA probes $V v A D F$ and $V v P R P 1$ showed over expression and induction of expression respectively in rooting-induced stem tissue compared with control tissue in the expected lines (Thomas and Schiefelbein, 2002b; Thomas et al., 2004).

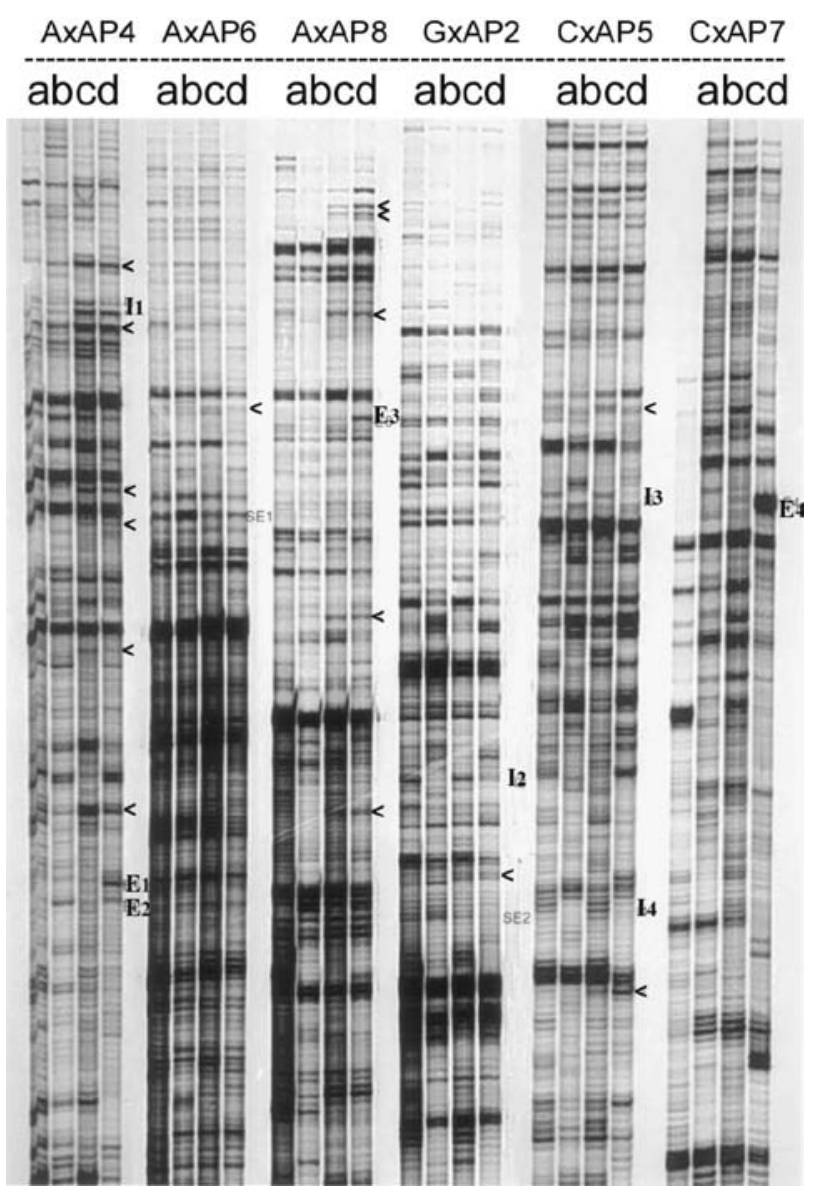

Figure 1. Autoradiograph of a denaturing differential display gel loaded with PCR amplified cDNA of control stem tissue from the in vitro grown stock (a), control stem tissue from ex vitro grown stock (b), microcuttings grown for $48 \mathrm{~h}$ in the in vitro rooting medium (c) and softwood cuttings $48 \mathrm{~h}$ post-planting in the ex vitro rooting medium (d). A, G and C represent anchored oligo-dT primers $\mathrm{H}$ $\mathrm{T}_{11} \mathrm{~A}, \mathrm{H}-\mathrm{T}_{11} \mathrm{G}$ and $\mathrm{H}-\mathrm{T}_{11} \mathrm{C}$ respectively and $\mathrm{AP}_{\mathrm{n}}$ represent the arbitrary primers of RNAImage kit1 (GenHunter Corporation, Nashville, TN). Arrow head indicates rooting or severing -related differentials, $\mathrm{I}_{1-4}$ represent the in vitro specific differentials and $\mathrm{E}_{1-4}$, the ex vitro specific differentials. 
Table 1. Description of in vitro or ex vitro specific differential bands selected from mRNA differential display (DD) autoradiographs for gene expression studies through Northern hybridization and the outcome of Northern blot

\begin{tabular}{llll}
\hline ID no. & Source (anchored $\times$ arbitrary primers) & Expression pattern in DD panel & Response in Northern hybridization \\
\hline $\mathrm{I}_{1}$ & AxAP4 & In vitro - induced & Identical expression in vitro and ex vitro \\
$\mathrm{I}_{2}$ & GxAP2 & In vitro - constitutive & Identical expression in vitro and ex vitro \\
$\mathrm{I}_{3}$ & CxAP5 & In vitro - constitutive & No signal in vitro and ex vitro \\
$\mathrm{I}_{4}$ & CxAP5 & In vitro - constitutive & Identical expression in vitro and ex vitro \\
$\mathrm{E}_{1}$ & AxAP4 & Ex vitro - induced & No signal in vitro and ex vitro \\
$\mathrm{E}_{2}$ & AxAP4 & Ex vitro - constitutive & Identical expression in vitro and ex vitro \\
$\mathrm{E}_{3}$ & AxAP8 & Ex vitro - induced & Identical expression in vitro and ex vitro \\
$\mathrm{E}_{4}$ & CxAP7 & Ex vitro - induced & Identical expression in vitro and ex vitro \\
\hline
\end{tabular}

The results thus suggested that no significant differences in gene expression pattern are detected between in vitro and ex vitro conditions during basic physiological processes such as rooting. Employing DD technique, we have isolated over 100 differentials expressed during rooting phase $(48 \mathrm{~h})$ leading to the cloning and characterization of some genes (Thomas and Schiefelbein, 2002a, b; Thomas et al., 2003). In the present study, the two experimental situations differed in a number of respects which are inherent to each one while severing, which is an integral component of propagation using cuttings and rooting induction were common to both the situations. The major differences between the in vitro and ex vitro situations included the concentration and duration of auxin treatment, age and type of tissue, exposure to different growing media and growing environment. Despite these vast differences, the gene expression was identical under the two environments during rooting. Whatever little difference observed in DD panels was attributable to false positives, which is one of the limitations of the mRNA differential display technique (Appel et al., 1999). The false positives may be attributable to genomic DNA contamination, PCR artifacts, comigration of cDNAs besides other causes (Appel et al., 1999; Martin and Pardee, 1999). The overall similarity in the banding pattern observed between in vitro and ex vitro cDNA in DD panels suggests that the false positives encountered here need not be a matter of concern in arriving at the conclusion.

In conclusion, mRNA differential display and subsequent Northern blot analyses of gene expression using RNA samples from control stem tissue of grape and stem tissue in rooting inductive phase have indicated that gene expression pattern is more or less identical under both in vitro and in vivo conditions.

\section{Acknowledgements}

The work was carried out at the University of Michigan and was supported by an Overseas Associateship Award to Pious Thomas by the Department of Biotechnology, Ministry of Science and Technology, Government of India. The grape culture 'Arka Neelamani' was supplied by the Indian Institute of Horticultural Research (ICAR), Bangalore, India.

\section{References}

Appel M, Bellstedt DU \& Gresshoff PM (1999) Differential display of eukaryotic mRNA: meeting the demands of the new millennium. J. Plant Physiol. 154: 561-570

GenHunter Corporation, Resources \& Technical Notes on Differential Display. www.GenHunter.com

Liang P (2002) A decade of differential display. BioTech. 33: 338-346

Liang P \& Pardee AB (1992) Differential display of eukaryotic messenger RNA by means of the polymerase chain reaction. Science 257: 967-971

Martin KJ \& Pardee AB (1999) Principles of differential display. In: Weissman SM (ed) Methods in Enzymology, cDNA Preparation and Characterization, Vol. 303 (pp. 234259). Academic Press, New York

Murashige T \& Skoog F (1962) A revised medium for rapid growth and bioassays with tobacco tissue cultures. Physiol. Plant 15: 473-497

Reuber TL \& Ausubel FM (1995) Differential mRNA display. In: Galbraith DW, Bohnert HJ \& Borque DP (eds) Methods in Cell Biology, Methods in Plant Cell Biology Part A, Vol. 49 (pp. 431-440). Academic Press, New York 
Thomas P (1998) Contribution of leaf lamina of grape nodal microcuttings to rooting, root vigour and plantlet growth in vitro. J. Plant Physiol. 153: 727-732

Thomas P \& Schiefelbein JW (2002a) An improved method for purification of RNA from stem tissue of grapevine and its use in mRNA profiling. Am. J. Enol. Viticult. 53: 231234

Thomas P \& Schiefelbein JW (2002b) Cloning and characterization of an actin depolymerizing factor gene from grape
(Vitis vinifera $\mathrm{L}$.) expressed during rooting in stem cuttings. Plant Sci. 162: 283-288

Thomas P \& Schiefelbein JW (2004) Roles of leaf in regulation of root and shoot growth from single node softwood cuttings of grape (Vitis vinifera). Ann. Appl. Biol. 144: 127-137

Thomas P, Lee MM \& Schiefelbein JW (2003) Molecular identification of proline-rich protein genes induced during root formation in grape (Vitis vinifera $\mathrm{L}$.) stem cuttings. Plant Cell Environ. 26: 1497-1504 